\title{
A phase I-II study of the histone deacetylase inhibitor valproic acid plus chemoimmunotherapy in patients with advanced melanoma
}

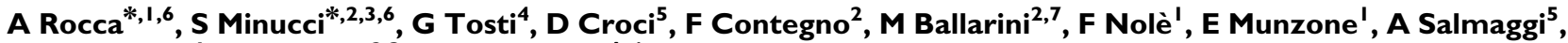 \\ A Goldhirsch', PG Pelicci, ${ }^{2,3}$ and A Testori*,4 \\ 'Department of Medicine, European Institute of Oncology, Via Ripamonti 435, Milan 2014I, Italy; ${ }^{2}$ Department of Experimental Oncology, European \\ Institute of Oncology, Via Ripamonti 435, Milan 20 I4I, Italy; ${ }^{3}$ University of Milan, Via Festa del Perdono 7, Milan 201 00, Italy; ${ }^{4}$ Melanoma and Muscle- \\ Cutaneous Sarcoma Division, European Institute of Oncology, Via Ripamonti 435, Milan 20 4 I, Italy; ${ }^{5}$ Central Laboratory, Istituto Nazionale Neurologico \\ 'Carlo Besta', Via Celoria II, Milan 20133, Italy
}

We explored in a phase I/II clinical trial the combination of valproic acid (VPA), a clinically available histone deacetylase inhibitor, with standard chemoimmunotherapy in patients with advanced melanoma, to evaluate its clinical activity, to correlate the clinical response with the biological activity of VPA and to assess toxicity. Patients were treated initially with VPA alone for 6 weeks. The inhibition of the target in non-tumour peripheral blood cells (taken as a potential surrogate marker) was measured periodically, and valproate dosing adjusted with the attempt to reach a measurable inhibition. After the treatment with valproate alone, dacarbazine plus interferon- $\alpha$ was started in combination with valproate. Twenty-nine eligible patients started taking valproate and 18 received chemoimmunotherapy and are assessable for response. We observed one complete response, two partial remissions and three disease stabilisations lasting longer than 24 weeks. With the higher valproate dosages needed to reach a measurable inhibition of the target, we observed an increase of side effects in those patients who received chemoimmunotherapy. The combination of VPA and chemoimmunotherapy did not produce results overtly superior to standard therapy in patients with advanced melanoma and toxicity was not negligible, casting some doubts on the clinical use of VPA in this setting (at least in the administration schedule adopted). British Journal of Cancer (2009) I 00, 28 -36. doi: I0.1038/sj.bjc.66048I7 www.bjcancer.com (C) 2009 Cancer Research UK

Keywords: histone deacetylase inhibitor; epigenetic therapy; valproic acid; chemoimmunotherapy; melanoma

Histone acetylation is dynamically regulated by the action of histone acetylases (HATs) and deacetylases (HDACs), and it is directly involved in the regulation of gene expression: hyperacetylated histones are found at expressed genes or at genes poised for transcription, whereas hypoacetylated histones are found at silent genes and in heterochromatin (Grunstein, 1997). Recent studies have shown that HATs/HDACs may be involved in acetylation/deacetylation of non-histone proteins (including cytoplasmic factors), which may modify functional properties of the substrate (Minucci and Pelicci, 2006). Deregulation of acetylation pathways may therefore exploit multiple strategies to lead to a transformed cell phenotype, and HDAC-dependent mechanisms have been involved in the pathogenesis of multiple tumours. For this reason, HDAC inhibitors (HDACis) have been tested extensively in vitro and in animal models of solid tumours. The results have shown that indeed HDACis are able to induce growth arrest, differentiation and/or apoptosis of essentially all tumour

\footnotetext{
* Correspondence: Dr A Rocca or Professor S Minucci or Dr A Testori; E-mails: a.rocca@irst.emr.it or saverio.minucci@ifom-ieo-campus.it or alessandro.testori@ieo.it

${ }^{6}$ These authors contributed equally to this work

${ }^{7}$ Current address: Congenia SRL, Via Adamello 16, Milan, Italy

Received 7 August 2008; revised 3 November 2008; accepted I5 November 2008
}

cell lines tested and induce tumour regression in animal models (Saunders et al, 1999; Marks et al, 2000). These observations have triggered the beginning of clinical studies in cancer patients; in some cases (i.e., T-cell cutaneous lymphoma), the results have been extremely promising, leading to the introduction of HDACis in the clinical practice (Piekarz et al, 2001; Byrd et al, 2005).

We have identified valproic acid (VPA), a commonly used antiepileptic drug, as an HDACi (Gottlicher et al, 2001). Beside its neurological effects (which are not due to its HDAC inhibitory activity), VPA is able to inhibit directly, although weakly, HDACs ( $\mathrm{Ki}$ in the millimolar range). As it has been used for decades and it is relatively 'safe', VPA has been therefore welcomed as a very attractive drug to enter this area, and several clinical studies have started to explore the potential of VPA as an anticancer therapy (Arce et al, 2006; Atmaca et al, 2007; Bishton et al, 2007; Candelaria et al, 2007; Munster et al, 2007; Rasheed et al, 2007, 2008).

In preclinical studies, VPA was used in murine models of acute promyelocytic leukaemia, where it caused disease remission, and in xenograft models of renal and lung metastasis, where it was highly effective in reducing the number and size of metastasis upon reinoculation of syngeneic mice with tumour cells (Gottlicher et al, 2001; Insinga et al, 2005).

Molecular evidences have been obtained to support the use of HDACis in the therapy of melanoma. Histone deacetylase inhibitors have been shown to induce strong decrease in the 
tumorigenic potential of melanoma-derived cell lines in animal models (xeno-transplantation), and to induce proapoptotic pathways in melanoma cells lines (Facchetti et al, 2004; Boyle et al, 2005). Strikingly, it has been suggested that resistance of melanoma cells to chemotherapy might - at least in some cases - be due to HDAC-mediated silencing of genes required for an optimal cell response to chemotherapy (such as Apaf-1) (Soengas et al, 2001; Soengas and Lowe, 2003), and preclinical data suggest that VPA should increase the sensitivity to chemotherapy. According to this model, critical proapoptotic pathways (silenced in cancer cells) should be reactivated following HDAC inhibition, leading to apoptosis (Minucci and Pelicci, 2006).

Additionally, HDACis have been suggested to modulate the immune response, through mechanisms which remain to be fully elucidated (Guo et al, 2006). In some cases, HDACi treatment has been proposed to potentiate immunoresponsive mechanisms, based on the induction of MHC molecules (Kato et al, 2007).

Taken together, these indications offer a rationale for the combination of HDACis with either standard chemotherapy or with immunotherapeutic approaches.

We describe the results of a phase I/II clinical trial assessing the activity of the combination of a standard chemoimmunotherapy plus VPA in patients with advanced melanoma.

\section{PATIENTS AND METHODS}

Patients with histological diagnosis of locally advanced inoperable or metastatic melanoma were eligible. Other selection criteria were as follows: age $>18$ years and $\leqslant 75$ years, ECOG performance status $0-2$, life expectancy of at least 6 months, measurable disease, adequate bone marrow function (white blood cell count $>3.0 \times 10^{9} / 1$ and platelet count $\left.>100 \times 10^{9} / 1\right)$, adequate renal function (serum creatinine $<120 \mu \mathrm{moll}^{-1}$ ) and hepatic function (serum bilirubin $<1.5 \mu \mathrm{moll}^{-1}$, AST $<60 \mathrm{UIl}^{-1}$ ), LDH levels $\leqslant 2$ fold the upper normal limits, written informed consent. Exclusion criteria were as follows: symptomatic cerebral or leptomeningeal involvement, other malignancy except basal or squamous carcinoma of the skin or in situ carcinoma of the cervix, non-malignant systemic diseases that would prevent from undergoing any of the treatment options, psychiatric or addictive disorders that would prevent from giving informed consent, pregnancy or breastfeeding, manifest severe hepatic and pancreatic dysfunction, porphyria, previous chemoimmunotherapy within 40 days.

All patients signed an institutional review board-approved informed consent form. The study was conducted in accordance with the principles of the Helsinki Declaration.

Baseline evaluation included the following: medical history, physical examination, ECOG performance status, haematology and blood chemistry, ECG, chest X-ray or CT scan of the thorax, CT scan or US of the abdomen. Target lesions were studied with CT scan at baseline and for response evaluation.

\section{Study design and treatment plan}

The study has been originally designed as a phase II clinical trial, with treatment plan involving an induction with VPA alone, whose dosage was gradually increased in each patient until achieving biologically active concentrations ('optimal concentration'), and then administered for 4 weeks, followed by a combined treatment with chemoimmunotherapy plus VPA. The aim of the induction phase was re-establishing the expression of genes, such as Apaf-1, that have been shown to be silenced by HDAC-involving mechanisms, and that are linked to response to chemotherapy (Soengas et al, 2001). Because the main aim of the trial was the evaluation of objective response to the combined treatment, although no formal assessment of response to the induction phase was planned, patients with overt disease progression during this phase were taken off study and received treatment at the discretion of the investigator.

We adopted a standard schedule of VPA administration used in epileptic patients, starting with $10 \mathrm{mg} \mathrm{kg}^{-1} \mathrm{day}^{-1}$ (in three divided doses) and increasing the dose weekly by $10 \mathrm{mg} \mathrm{kg}^{-1} \mathrm{day}^{-1}$ (with a maximum allowed dose of $30 \mathrm{mg} \mathrm{kg}^{-1} \mathrm{day}^{-1}$ ), up to the achievement of adequate plasmatic concentrations. These doses usually allow to maintain steady-state plasma concentrations between 50 and $125 \mathrm{mgl}^{-1}$ (DeVane, 2003), potentially in the range required to modulate the target (HDACs). Prudent initial doses were chosen to avoid haematological and neurological side effects that are dose related and could be more unpredictable at higher doses, due to the nonlinear metabolism/clearance and protein binding of VPA (DeVane, 2003). Furthermore, the use of these doses of VPA as anticonvulsant drug in association with chemotherapy in patients with cerebral tumours had been reported as feasible, although a slight increase in haematological toxicity is described (Bourg et al, 2001). Valproic acid was supplied in tablets from 200 and $500 \mathrm{mg}$, and total daily dose was rounded off to the nearest dose allowed by the available tablets, and administered in three divided doses every $8 \mathrm{~h}$.

After 4 weeks of full dose VPA, patients received dacarbazine, $800 \mathrm{mg} \mathrm{m}^{-2}$ intravenously every 21 days, and interferon- $\alpha$, 600.000 IU twice daily subcutaneously, while continuing VPA at the same dose. Treatment was planned for a maximum of four courses of dacarbazine and 6 months of interferon- $\alpha$, or until disease progression. Antiemetic prophylaxis with serotonin antagonists and corticosteroids was used before administering dacarbazine.

The analysis of VPA plasmatic levels and histone acetylation changes for the first 10 patients showed that the dose of $30 \mathrm{mg} \mathrm{kg}^{-1}$ day $^{-1}$ did not allow either the achievement of the optimal plasmatic concentration of free drug $\left(50-100 \mathrm{mgl}^{-1}\right)$ in most patients or a consistent increase in histone acetylation. The study design was therefore modified into a phase I/II clinical trial, with an amendment to the protocol, introducing a second dose level of maximum $90 \mathrm{mg} \mathrm{kg}^{-1} \mathrm{day}^{-1}$ of VPA, based on plasmatic levels achieved with the $30 \mathrm{mg} \mathrm{kg}^{-1} \mathrm{day}^{-1}$ dose and on expected toxicity (Figure 1). Seven patients who had already completed the induction phase at $30 \mathrm{mg} \mathrm{kg}^{-1}$ day $^{-1}$ as maximum dose had weekly dose escalation by $30 \mathrm{mg} \mathrm{kg}^{-1}$ day $^{-1}$ during the combination phase, whereas new patients started the induction phase with $30 \mathrm{mg} \mathrm{kg}^{-1} \mathrm{day}^{-1}$ and increased weekly by $30 \mathrm{mg} \mathrm{kg}^{-1} \mathrm{day}^{-1}$ until the achievement of the required plasmatic concentration, which was continued for 4 weeks alone and then in combination with dacarbazine and interferon- $\alpha$.

The primary end point was the response rate with the combination of VPA plus chemoimmunotherapy. Secondary end points were the assessment of the toxicity of VPA, alone and combined with chemoimmunotherapy, the evaluation of clinical benefit (defined as the overall rate of objective response plus disease stabilisation longer than 24 weeks), response duration and progression-free survival. Histone acetylation levels were measured in peripheral blood mononuclear cells (PBMCs) to assess correlation with patient response.

\section{Toxicity evaluation and dose modifications}

Patients were assessed for toxicity weekly during the induction with VPA alone and before every cycle of chemotherapy during the combined treatment, with clinical examination and laboratory evaluation. Toxicity was graded using the Common Toxicity Criteria (CTC) Version 2.0 (http://ctep.cancer.gov/forms/ CTCv20_4-30-992.pdf), and common dose modifications or delays were adopted for chemotherapy in case of toxicity. Valproate dose was reduced (one step at a time, following the reverse of the escalation plan for each dose level) in case of grade 2 toxicity attributable to the drug, and temporarily stopped in case of grade 


\begin{tabular}{|l|l|l|l|l|l|l|l|l|}
\hline Week 1 & Week 2 & Week 3 & Week 6 & Subsequent weeks \\
\hline
\end{tabular}

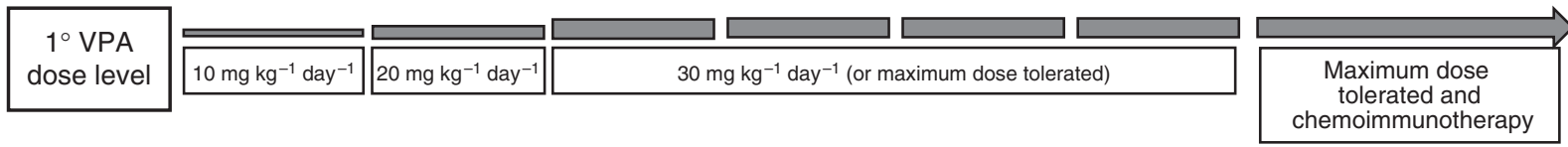
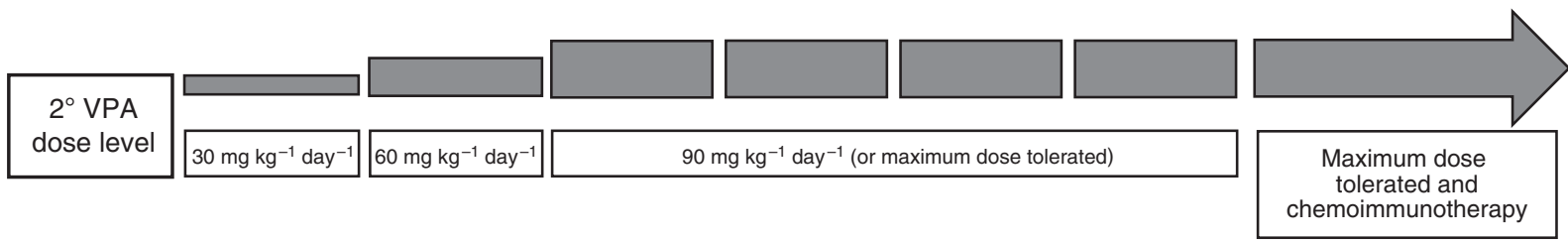

Figure I Valproic acid dose escalation scheme. See the Patients and Methods section for a more detailed description of the treatment schedule and rationale.

$3-4$ side effects, until resolution to at least grade 2 . Treatment was then resumed with dose reduction as in case of grade 2 toxicity.

\section{Response assessment}

Assessment of response was done before each cycle of chemotherapy by physical examination in case of superficial lesions. Computerized chemography for assessment of target lesions was done after 8 weeks of combined therapy and repeated every 8 weeks thereafter (no assessment was planned at the end of the induction period). Tumour response was defined according to RECIST criteria (Therasse et al, 2000).

\section{VPA plasma levels and histone acetylation in peripheral blood cells}

Measurement of VPA plasma levels (absolute and free levels) was done at the end of the 1st week of treatment (four times daily: 0800 hours, before first daily administration; 1100 hours, $3 \mathrm{~h}$ post-dose; 1500 hours, $7 \mathrm{~h}$ post-dose; 1800 hours, $2 \mathrm{~h}$ after the second daily dose) and repeated at the beginning of the combination phase and weekly thereafter (at 0800 hours, before first administration) or whenever new drugs were introduced in the treatment of the patient. To define the 'optimal concentrations' (biologically active concentrations), we followed two criteria: (a) the plasmatic concentrations of VPA. We measured both total and free levels of the drug by FPIA method (fluorescence polarised immunoassay - Abbott Industries). The free levels were performed on plasma ultrafiltrates (Levy et al, 1984). Given the molecular weight and its relatively low potency ( $\mathrm{Ki}$ in the millimolar range), we aimed to reach concentrations of free VPA in the millimolar range (50$100 \mathrm{mgl}^{-1}$ or higher); (b) the levels of induction of histone acetylation in PBMCs. We used cytofluorimetric techniques to evaluate histone acetylation levels in PBMCs, which in preclinical models of acute myeloid leukaemia have been good indicators of the efficacy of VPA treatment (Ronzoni et al, 2005). Assessments were done at the end of the second week of treatment, at the beginning of the combination phase and weekly thereafter. The levels of histone acetylation in PBMCs from representative patients are reported in Figure 2, together with results from a cell line treated with trichostatin A as positive control.

\section{Statistical considerations}

The main end point was the best tumour response. Using a two stage, phase II optimal design, powered to choose between an acceptable response rate of $40 \%$ and an unacceptable one of $20 \%$, at the $5 \%$ significance level and $90 \%$ power, 19 patients were needed in the first stage and if four or less had an objective response than the trial had to be closed because of poor response. If five or more patients had a response, the trial would go on to the second stage by recruiting further 35 patients to reach a total of 54 . If 16 patients or more had an objective response, it could be concluded that a response rate of $40 \%$ is possible and one of $20 \%$ unlikely.

Because the main aim was to evaluate the overall activity of the combination of VPA plus chemoimmunotherapy, the assessment of treatment activity is performed on patients actually receiving the combined treatment, but results of an intent-to-treat analysis on all eligible patients are also reported.

Time-to-event end points were estimated using the method of Kaplan and Meier. Progression-free survival was measured from the first day of study treatment to the date of disease progression. The association between paired continuous variables was assessed by Spearman's correlation coefficient. Statistical analysis was performed with R (R Development Core Team, 2006).

\section{RESULTS}

Between September 2001 and February 2002, 32 patients referred to the Division of Medical Oncology and to the Melanoma and Muscle-Cutaneous Sarcoma Division of the European Institute of Oncology were entered sequentially onto the study. Two patients turned out to be ineligible, one with no evidence of disease and the other because of a second malignancy. Among 30 eligible patients, 28 were assessable for toxicity, whereas one patient never started treatment because of early refusal and one never reached meaningful plasmatic levels of VPA because of malabsorption. Eighteen patients received the combined treatment with VPA and chemoimmunotherapy and were assessable for response. Ten patients were not assessable, eight for early progressive disease (before starting chemotherapy), one for non-compliance and one who was admitted to another hospital and lost to follow-up. The characteristics of all 32 registered patients are listed in Table 1. Apart from most patients being pretreated for metastatic disease, the distribution of main features is roughly comparable with that from most recent large trials of first-line biochemotherapy (Eton et al, 2002; Ridolfi et al, 2002; Bajetta et al, 2006).

Overall, 29 patients started the induction phase, receiving VPA alone for a median duration of 6 weeks (range 3-10 weeks), including dose escalation and 4 weeks at maximum dose. Eighteen 

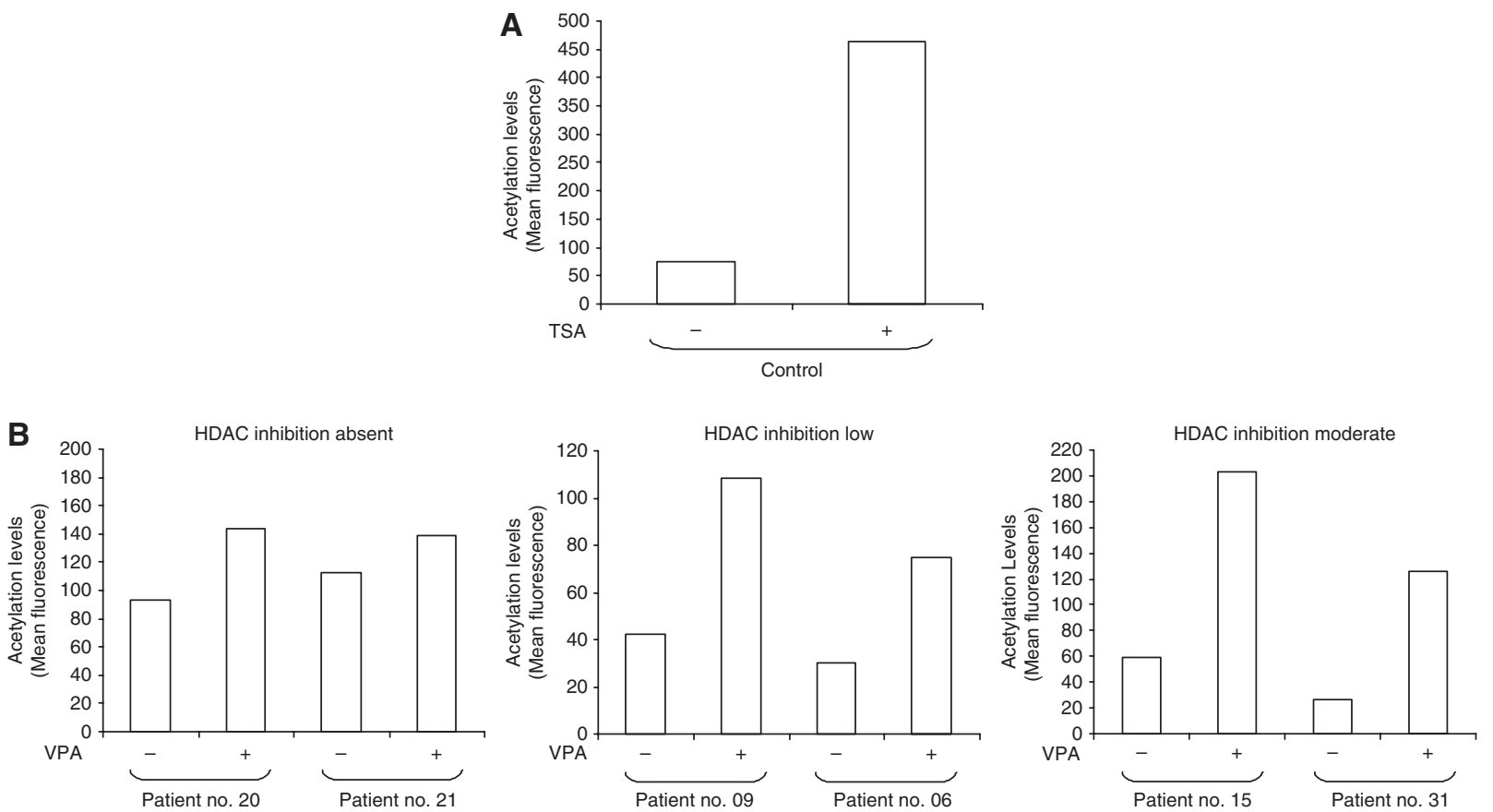

Figure 2 (A) FACS analysis of reference U937 cells not treated and treated with $50 \mathrm{ng} \mathrm{m}^{-1}$ of trichostatin A (TSA) for $4 \mathrm{~h}$. The reference cells were analysed at every measurement, to ensure consistency in machine settings and blank determination (see also Ronzoni et al, 2005). (B) Representative FACS analyses of patients untreated or treated for 2 weeks with VPA. Peripheral blood mononuclear cells were collected and analysed as described in the Patients and Methods section. Patients shown in the figure have been classified according to the level of increase in histone acetylation: absent ( $<2$ fold), low (twoto three-fold), moderate ( $>3$ fold).

patients went on the combination phase, receiving a median of four courses of chemotherapy (range 1-6) in association with interferon- $\alpha$, with 11 patients completing the planned programme of four courses (one responsive patient received six courses of chemotherapy).

Table 2 illustrates the amount of VPA received by patients, reporting the maximum daily dose assumed and the median duration of treatment at the maximum dose.

Among the initial cohort of 10 patients treated at the first dose level of VPA, three did not undergo dose escalation above $10 \mathrm{mg} \mathrm{kg}^{-1} \mathrm{day}^{-1}$, one for non-compliance and two because of disease progression. The other seven reached the maximum dose of $30 \mathrm{mg} \mathrm{kg}^{-1} \mathrm{day}^{-1}$, but stopped treatment because of disease progression before starting chemotherapy. In the second cohort of patients, 15 reached a dose of VPA of $60 \mathrm{mg} \mathrm{kg}^{-1} \mathrm{day}^{-1}$, without further escalation because of toxicity, and four reached the planned maximum dose of $90 \mathrm{mg} \mathrm{kg}^{-1} \mathrm{day}^{-1}$, which was later reduced or temporarily suspended in all of them; 11 completed the planned treatment with VPA plus four courses of chemotherapy and 6 months of interferon- $\alpha$; the other eight patients stopped treatment early, because of disease progression.

The median duration of treatment with an optimal dose of VPA was less than 1 month. Table 3 shows the toxicity registered according to the maximum dose of VPA. During the induction phase, most side effects were mild and included myelosuppression, gastrointestinal and hepatic toxicity and neurological toxicity; more serious side effects were rare, and more likely due to disease progression (see below). During the combination phase, myelosuppression was more severe. Most non-haematological side effects were mild, but neurological toxicity exceeded that seen during the induction phase.

Two patients had serious adverse events possibly related to VPA. One had grade 4 cerebral haemorrhage, headache and coma, and multiple grade 3 neurological symptoms and grade 3 hypocalcemia. Laboratory parameters, including coagulation tests, were normal. An MRI of the brain showed a massive haemorrhage in the right cerebral hemisphere; a neuroradiological consultant favored the hypothesis of bleeding of a cerebral metastasis, although the patient was not known to have cerebral metastases before entering the study. The patient was taking VPA at the dose of $60 \mathrm{mg} \mathrm{kg}^{-1} \mathrm{day}^{-1}$; total VPA concentration was $148.9 \mathrm{mg} \mathrm{l}^{-1}$ and free VPA concentration was $51 \mathrm{mgl}^{-1}$. Histone acetylation in peripheral blood leukocytes was increased 2.9 times over the baseline values. Four days after suspension, VPA total and free concentrations were dropped to 3.1 and $0.2 \mathrm{mgl}^{-1}$, respectively. The patient was also receiving dacarbazine and interferon- $\alpha$. Consciousness recovered to normal, but the patient had permanent left hemiparesis.

A second patient had neurological toxicity (grade 3 confusion, stupor, ataxia, urinary incontinence and grade 2 tremor) probably related to VPA while taking a dose of $35 \mathrm{mg} \mathrm{kg}^{-1}$ day $^{-1}$ plus dacarbazine and interferon- $\alpha$. Symptoms disappeared after suspension of VPA.

Three other serious adverse events were considered unrelated to the study treatment and attributed to tumour progression: one case of pleural effusion with severe dyspnoea, one case of cachexia and one case of grade 4 anaemia with haematuria due to melanoma progression involving the bladder.

The two bleeding episodes reported (one cerebral haemorrhage with combined therapy and one haematuria with VPA alone) could suggest a possible bleeding diathesis, potentially related to the interference of VPA with platelets and haemostasis, but this possibility was not supported by alterations in common coagulation tests.

The treatment produced one complete remission, two partial remissions and three disease stabilisation lasting at least 24 weeks. Twelve patients had progressive disease or short-term ( 2 months) stabilisation, and 12 were not evaluable for response and were considered as treatment failures. The overall response rate is thus 10\% (95\% CI: 2-27\%) when considering all eligible patients 
( $n=30)$, and $17 \%$ (95\% CI: $4-41 \%)$ when considering only evaluable patients $(n=18)$. The rate of clinical benefit, in terms of objective response or disease stabilisation lasting at least 24 weeks, is $20.7 \%$ (95\% CI: $8.0-39.7 \%)$ on all eligible patients and $33.3 \%$

Table I Patient characteristics

\begin{tabular}{|c|c|}
\hline Characteristic & $\mathbf{N}$ \\
\hline \multicolumn{2}{|l|}{ Sex } \\
\hline Male & 17 \\
\hline Female & 15 \\
\hline \multicolumn{2}{|l|}{ Age, years } \\
\hline Median & 51 \\
\hline Range & $23-72$ \\
\hline \multicolumn{2}{|l|}{ ECOG performance status } \\
\hline 0 & 26 \\
\hline I & 5 \\
\hline 2 & I \\
\hline \multicolumn{2}{|l|}{ Number of involved sites } \\
\hline 0 & I \\
\hline I (sc/ln) & $6(4 / 2)$ \\
\hline 2 & 9 \\
\hline$>2$ & 16 \\
\hline \multicolumn{2}{|l|}{ Tumor site } \\
\hline MO & I \\
\hline Skin, sc, In & । \\
\hline Lung & 2 \\
\hline Other visceral/(CNS) & $18 /(2)$ \\
\hline \multicolumn{2}{|l|}{ Previous treatments } \\
\hline Surgery & 31 \\
\hline \multicolumn{2}{|l|}{ Adjuvant treatment } \\
\hline CT (DTIC) & । \\
\hline IT $(\mathrm{IF}-\alpha)$ & 12 \\
\hline None & 19 \\
\hline \multicolumn{2}{|l|}{ Treatment for metastatic disease } \\
\hline CT (DTIC/CVD) & $4(4 / 1)$ \\
\hline $\mathrm{IT}(\mathrm{IF}-\alpha)$ & 5 \\
\hline $\mathrm{CT}+\mathrm{IT}$ & 8 \\
\hline DTIC $\circ$ CVD + IF- $\alpha( \pm I L-2)$ & 7 \\
\hline DTIC o CVD+IL-2 & 1 \\
\hline Hyperthermic isolated limb perfusion & । \\
\hline None & 14 \\
\hline \multicolumn{2}{|l|}{ N. lines for metastatic disease } \\
\hline $0 / 1 / 2 />2$ & |4/8/6/4 \\
\hline Median (range) & I $(0-5)$ \\
\hline
\end{tabular}

Abbreviations: $\mathrm{sc}=$ subcutaneous; $\mathrm{In}=$ lymph nodes; $\mathrm{CNS}=$ central nervous system; $E C O G=$ Eastern Cooperative Oncology Group; $C T=$ chemotherapy; $\mathrm{IT}=$ immunotherapy; $\quad \mathrm{IF}-\alpha=$ interferon- $\alpha ; \quad \mathrm{DTIC}=$ dacarbazine; $\quad \mathrm{CVD}=$ cisplatin vinblastine dacarbazine.
(95\% CI: $13.3-59.0 \%)$ on evaluable patients. The median time to progression (TTP) is 3.8 months.

The study was closed early for poor activity, after the enrolment of 18 evaluable patients in the first stage, because only three responses were seen by that time, while five or more responses should have been registered among the first 19 patients to proceed to the second stage. Most patients who obtained a clinical benefit were pretreated with interferon- $\alpha$ as adjuvant (three patients) or palliative (three patients) therapy; one patient who achieved disease stabilisation was pretreated with dacarbazine for advanced disease. The TTP has been for at least 40 weeks in four patients.

Plasmatic levels of total and free VPA were measured in 27 patients, and maximum levels reached are reported in Table 4. There is a statistically significant correlation between VPA dose and both total (Spearman's $R=0.65, P=0.0002$ ) and free (Spearman's $R=0.63, P=0.0005$ ) VPA plasmatic levels, as well as between increase in histone acetylation and both total (Spearman's $R=0.44, P=0.02$ ) and free (Spearman's $R=0.45, P=0.02$ ) VPA plasmatic levels (Figure 3 ). On the contrary, there was no clear association between dose and increase in histone acetylation (Spearman's $R=0.22, P=0.3$ ). There was no correlation between histone acetylation and response. All patients who achieved greater than twice increase in histone acetylation had disease progression (data not shown).

\section{DISCUSSION}

Stage IV melanoma has a poor prognosis, with median survival shorter than 1 year and a negligible proportion $(\leqslant 5 \%)$ of patients alive at 5 years (Lee et al, 2000) after chemotherapy or immunotherapy. Although dacarbazine is considered the standard therapy, a meta-analysis of randomised trials showed a response rate of $16.9 \%$ (95\% CI: 14.7-19.1\%) (Huncharek et al, 2001), and randomised phase III trials with audited response assessment yielded a response rate as low as 7\% (Avril et al, 2004). Despite encouraging results in phase II studies, neither polychemotherapy (Chapman et al, 1999) nor biochemotherapy (Eton et al, 2002; Ridolfi et al, 2002; Bajetta et al, 2006) have shown clear advantages over single-agent dacarbazine in randomised trials. Therefore, new therapeutic strategies are clearly needed.

Histone deacetylase inhibitors are considered among the most promising new anticancer drugs, and several agents have recently entered clinical trials. The use of HDACis has been suggested also for the treatment of patients with melanoma (Boyle et al, 2005). The use of VPA is extremely appealing. Although not as potent as other HDACis developed more recently, this drug has been for decades in the treatment of epilepsy, with generally mild side effects reported. Valproic acid has been shown recently to be active on melanoma cell lines, further suggesting a potential use in this disease (Valentini et al, 2007). In our study, however, the

Table 2 Maximum dose of valproic acid (VPA) received during the entire treatment period ${ }^{\mathrm{a}}$

\begin{tabular}{|c|c|c|c|c|}
\hline & \multicolumn{4}{|c|}{ Maximum VPA dose $\left(\mathrm{mg} \mathrm{kg}^{-1} \mathrm{day}^{-1}\right)$} \\
\hline & \multicolumn{2}{|c|}{ (First cohort, $N=10$ ) } & \multicolumn{2}{|c|}{ (Second cohort, $N=19$ ) } \\
\hline Number of patients & 3 & 7 & 15 & 4 \\
\hline Median duration at maximum dose (days) & 8 & 16 & 26 & 19 \\
\hline Temporary suspension (number of patients) & I & 1 & 4 & 3 \\
\hline
\end{tabular}

${ }^{a}$ On 29 patients who actually started VPA assumption. ${ }^{b}$ Five serious adverse events, I non-compliance, 12 treatment failures. 
Table 3 Toxicity of valproic acid (VPA) a

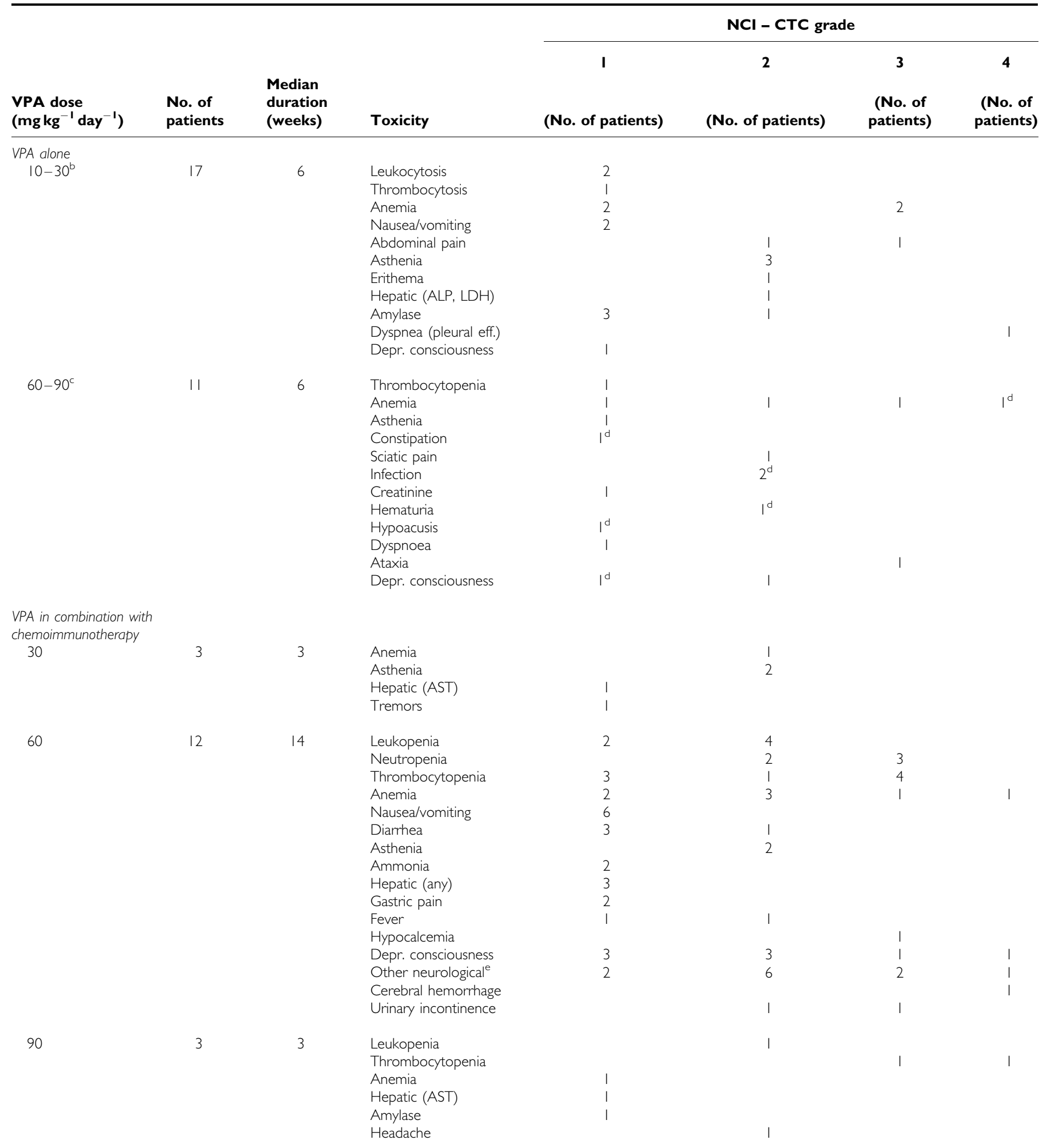

${ }^{\mathrm{a}}$ On 28 assessable patients. Each patient is reported in each section of the table (VPA alone, and VPA in combination with chemoimmunotherapy) within the row corresponding to the highest dose level he received during the pertinent period of therapy. Some patients had dose reductions of VPA already during the induction phase, and others had dose escalation during the combination phase. All patients except one had some kind of toxicity. ${ }^{b}$ Three patients at $10 \mathrm{mg} \mathrm{kg}^{-1} \mathrm{day}^{-1}, 14$ patients at $30 \mathrm{mg} \mathrm{kg}{ }^{-1}$ day ${ }^{-1}$. ${ }^{\mathrm{C}} 10$ patients at $60 \mathrm{mg} \mathrm{kg}^{-1} \mathrm{day}^{-1}$, one patient at $90 \mathrm{mg} \mathrm{kg}^{-1} \mathrm{day}^{-1} .{ }^{1} 90 \mathrm{mg} \mathrm{kg}^{-1}$ day ${ }^{-1}$, with bladder progression of disease. ${ }^{e}$ Vertigo, hallucinations, headache, speech impairment, mood alteration, memory loss, paraesthesia, seizures, tremors, confusion. 
Table 4 Plasmatic levels of total and free VPA

\begin{tabular}{|c|c|}
\hline Total VPA plasmatic levels $\left(\mathrm{mg} \mathrm{l}^{-1}\right)$ & No. of patients \\
\hline $0-50$ & 0 \\
\hline $51-100$ & 8 \\
\hline $101-150$ & 14 \\
\hline$|5|-200$ & 5 \\
\hline
\end{tabular}

Free VPA plasmatic levels $\left(\mathrm{mg} \mathrm{I}^{-1}\right)$

No. of patients

$$
\leqslant 10
$$

$10.1-20$

$20.1-30$

$30.1-40$

$40.1-50$

$50.1-60$

Abbreviation: VPA = valproic acid.
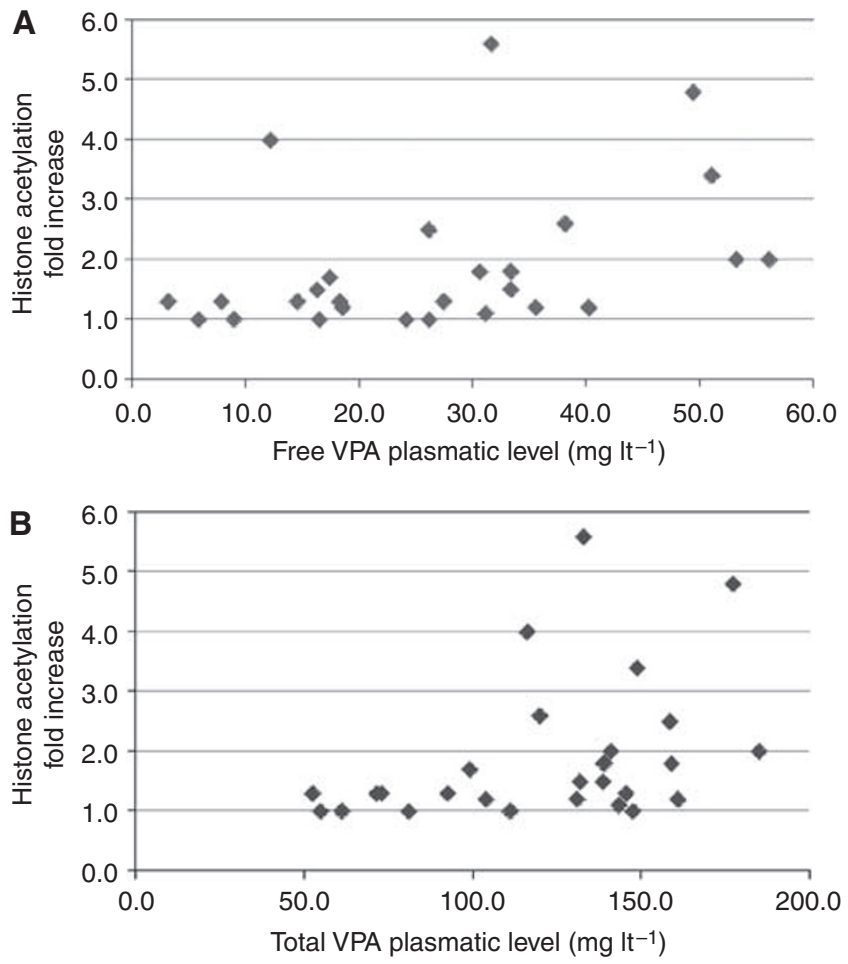

Figure 3 Relationship between free $(\mathbf{A})$ and total $(\mathbf{B})$ valproic acid (VPA) plasmatic levels and fold increase in histone acetylation in peripheral blood mononuclear cells over baseline values. Data refer to the maximum values of plasmatic VPA and the maximum fold increase in histone acetylation reached by each patient during treatment at the maximal dose of VPA. For a statistical analysis of the data, see the Results section. Note that the patients who showed the highest increase in histone acetylation levels ( $>4$ fold) did not maintain this increase at repeated measurements, notwithstanding the maintenance of the VPA dose.

combination of dacarbazine, interferon- $\alpha$ and VPA did not appear to be clearly superior in terms of activity to what is expected from standard therapy.

The use of VPA as HDACi was hampered by a series of problems. Valproic acid dosage must be adjusted gradually, requiring a few weeks before reaching the full dose in most patients, which may result in disease progression in aggressive tumours. Eight patients in our study had early disease progression, before starting chemotherapy. The drug turned out to be less tolerable than when used alone for treatment of epilepsy, particularly with dosages of $60 \mathrm{mg} \mathrm{kg}^{-1} \mathrm{day}^{-1}$ or higher. The median duration of treatment with an optimal dose of VPA was less than 1 month, and most patients had dose reductions or temporary interruption of treatment for toxicity. Two serious adverse events, a grade 4 bleeding of a cerebral metastasis and a grade 3 neurological toxicity, were possibly related to the study drugs and required definitive interruption of VPA.

Preclinical studies have shown that indeed VPA inhibits efficiently HDACs, and extended survival with tumour regression in several cancer models (Insinga et al, 2005). A comparison of the use of VPA in mice and human patients, however, reveals several important differences. In fact, we were able to reach free plasmatic concentrations of VPA $>2 \mathrm{~mm}$ in our mice models $\left(>300 \mathrm{mgl}^{-1}\right.$ of free VPA) (Insinga et al, 2005). In contrast, only $44 \%$ of the patients showed free VPA levels $>30 \mathrm{mgl}^{-1}$ (equivalent to a concentration $>0.2 \mathrm{~mm}$ ) and just three patients reached a free VPA concentration $>50 \mathrm{mgl}^{-1}(>0.3 \mathrm{mM})$. These concentrations are suboptimal, and the increase in histone acetylation levels observed in PBMCs of the patients was never as high as those observed in preclinical models. In fact, in murine models of leukaemia, we were unable to achieve clinical responses (i.e., disease remission and extended survival) at free VPA levels below $1 \mathrm{~mm}$ (A Insinga, PG Pelicci and S Minucci, unpublished observations). At those levels, the average increase in histone acetylation levels observed in blood-derived mononuclear cells (which in leukaemic mice are a mix of leukaemic cells and PBMCs) is always $>4$ fold, an increase which was not observed in this clinical study. Only two patients showed a $>4$ fold increase in histone acetylation, but those increases were not observed throughout the entire treatment regimen, and therefore cannot be considered as true exceptions to this model. In the absence of a set of patients, which show sustained high levels of histone acetylation following treatment, however, it cannot be claimed that the relationship observed in the leukaemic murine models holds true in the clinical setting, and further studies will be required.

From our study it appears difficult to further increase VPA doses in continuous administration, without incurring in undesired, serious side effects, at least when combined with dacarbazine and interferon- $\alpha$. Other studies have reported the feasibility and partial activity of a continuous oral treatment with lower doses of VPA of $30-40 \mathrm{mg} \mathrm{kg}^{-1}$ day $^{-1}$ in combination with hydralazine and chemotherapy (Arce et al, 2006; Candelaria et al, 2007), and the potential to improve results of chemotherapy alone and to overcome chemotherapy resistance in solid tumours (Candelaria et al, 2007). It is not possible to discern the relative contribution of the two epigenetic drugs to these results, nor if the addition of hydralazine could allow for a reduction in VPA doses without jeopardising its activity. In our study, the mean plasmatic level of total VPA in patients receiving doses $\leqslant 30 \mathrm{mg} \mathrm{kg}^{-1} \mathrm{day}^{-1}$ was $88 \mathrm{mgl}^{-1}$, producing a 1.7 mean fold increase in histone acetylation, which is considered insufficient from preclinical data. For patients receiving doses $>30 \mathrm{mg} \mathrm{kg}^{-1}$ day $^{-1}$, the mean plasmatic concentration was $136 \mathrm{mgl}^{-1}$ with a two-fold mean increase in histone acetylation. Although we found a correlation between VPA dose and plasmatic levels and between plasmatic levels and histone acetylation changes, there was no significant correlation between dose and histone acetylation changes. Individual differences in VPA pharmacokinetics and pharmacodynamics, related for example to baseline values of histone acetylation and activity of HDACs, could explain the lack of a direct relationship between VPA dose and biological activity, which hampers the definition of the optimal dose of this agent. Other studies have explored cyclic schedules. With an intravenous administration of VPA daily for 5 consecutive days in 21-day cycles (Atmaca et al, 2007), the MTD was $60 \mathrm{mg} \mathrm{kg}^{-1} \mathrm{day}^{-1}$ and histone hyperacetylation and HDAC downregulation were detected on PBMCs in the majority of patients. The administration of a loading dose (either intravenously or orally) of VPA followed by 5 oral doses administered every $12 \mathrm{~h}$, preceding the administration 
of epirubicin $75-100 \mathrm{mg} \mathrm{m}^{-2}$, allowed the achievement of $140 \mathrm{mg} \mathrm{kg}^{-1}$ day $^{-1}$ as recommended dose of VPA for phase II studies (Munster et al, 2007), showing a significant correlation among histone $\mathrm{H} 4$ acetylation and VPA dose and plasmatic concentration, as well as clinical antitumor activity.

Different administration schemes or combinations with other chemotherapic regimens could play, therefore, an important role in the determination of the response to VPA. Conflicting results have been reported about the correlation among VPA dose, plasmatic concentration and changes in histone acetylation, and more data are needed to better define these relationships and the value of these parameters as surrogate end points. The same considerations could apply to other, more potent HDACis, such as vorinostat and belinostat, which appear promising in enhancing the activity of chemotherapy regimens (Ramalingam et al, 2007; Sinha et al, 2007).

In conclusion, continuous oral treatment with VPA at doses of $60 \mathrm{mg} \mathrm{kg}^{-1} \mathrm{day}^{-1}$ or greater seems not feasible in patients with advanced melanoma receiving concomitant dacarbazine and interferon- $\alpha$. Administration of VPA with different schedules (e.g., cyclically in concomitance with chemotherapy, or continuously but at lower doses in concomitance with other epigenetic or biological drugs), however, could be feasible and treatment of a higher number of patients could reveal subsets of responsive patients. Further development of VPA as HDACi in patients with solid tumours requires careful consideration of the treatment schedule, synergism with other drugs and ideally the definition of predictors of response.

\section{ACKNOWLEDGEMENTS}

We thank Dr M Faretta and S Ronzoni (EIO Imaging facility) for their help. Work in the laboratory of SM is funded by AIRC, EEC (Epitron), MIUR.

\section{REFERENCES}

Arce C, Perez-Plasencia C, Gonzalez-Fierro A, de la Cruz-Hernandez E, Revilla-Vazquez A, Chavez-Blanco A, Trejo-Becerril C, Perez-Cardenas E, Taja-Chayeb L, Bargallo E, Villarreal P, Ramirez T, Vela T, Candelaria M, Camargo MF, Robles E, Duenas-Gonzalez A (2006) A proof-of-principle study of epigenetic therapy added to neoadjuvant doxorubicin cyclophosphamide for locally advanced breast cancer. PLOS ONE 1: e98

Atmaca A, Al-Batran SE, Maurer A, Neumann A, Heinzel T, Hentsch B, Schwarz SE, Hovelmann S, Gottlicher M, Knuth A, Jager E (2007) Valproic acid (VPA) in patients with refractory advanced cancer: a dose escalating phase I clinical trial. Br J Cancer 97: 177-182

Avril MF, Aamdal S, Grob JJ, Hauschild A, Mohr P, Bonerandi JJ, Weichenthal M, Neuber K, Bieber T, Gilde K, Guillem Porta V, Fra J, Bonneterre J, Saiag P, Kamanabrou D, Pehamberger H, Sufliarsky J, Gonzalez Larriba JL, Scherrer A, Menu Y (2004) Fotemustine compared with dacarbazine in patients with disseminated malignant melanoma: a phase III study. J Clin Oncol 22: 1118-1125

Bajetta E, Del Vecchio M, Nova P, Fusi A, Daponte A, Sertoli MR, Queirolo P, Taveggia P, Bernengo MG, Legha SS, Formisano B, Cascinelli N (2006) Multicenter phase III randomized trial of polychemotherapy (CVD regimen) versus the same chemotherapy (CT) plus subcutaneous interleukin-2 and interferon-\{alpha $\} 2 \mathrm{~b}$ in metastatic melanoma. Ann Oncol 17: $571-577$

Bishton M, Kenealy M, Johnstone R, Rasheed W, Prince HM (2007) Epigenetic targets in hematological malignancies: combination therapies with HDACis and demethylating agents. Expert Rev Anticancer Ther 7: $1439-1449$

Bourg V, Lebrun C, Chichmanian RM, Thomas P, Frenay M (2001) Nitroso-urea-cisplatin-based chemotherapy associated with valproate: increase of haematologic toxicity. Ann Oncol 12: 217-219

Boyle GM, Martyn AC, Parsons PG (2005) Histone deacetylase inhibitors and malignant melanoma. Pigment Cell Res 18: 160-166

Byrd JC, Marcucci G, Parthun MR, Xiao JJ, Klisovic RB, Moran M, Lin TS, Liu S, Sklenar AR, Davis ME, Lucas DM, Fischer B, Shank R, Tejaswi SL, Binkley P, Wright J, Chan KK, Grever MR (2005) A phase 1 and pharmacodynamic study of depsipeptide (FK228) in chronic lymphocytic leukemia and acute myeloid leukemia. Blood 105: 959-967

Candelaria M, Gallardo-Rincon D, Arce C, Cetina L, Aguilar-Ponce J, Arrieta O, Gonzalez-Fierro A, Chavez-Blanco A, de la Cruz-Hernandez E, Camargo M, Trejo-Becerril C, Perez-Cardenas E, Perez-Plasencia C, TajaChayeb L, Wegman-Ostrosky T, Revilla-Vazquez A, Duenas-Gonzalez A (2007) A phase II study of epigenetic therapy with hydralazine and magnesium valproate to overcome chemotherapy resistance in refractory solid tumors. Ann Oncol 18: 1529-1538

Chapman PB, Einhorn LH, Meyers ML, Saxman S, Destro AN, Panageas KS, Begg CB, Agarwala SS, Schuchter LM, Ernstoff MS, Houghton AN, Kirkwood JM (1999) Phase III multicenter randomized trial of the Dartmouth regimen versus dacarbazine in patients with metastatic melanoma. J Clin Oncol 17: 2745-2751

DeVane CL (2003) Pharmacokinetics, drug interactions, and tolerability of valproate. Psychopharmacol Bull 37(Suppl 2): 25-42
Eton O, Legha SS, Bedikian AY, Lee JJ, Buzaid AC, Hodges C, Ring SE, Papadopoulos NE, Plager C, East MJ, Zhan F, Benjamin RS (2002) Sequential biochemotherapy versus chemotherapy for metastatic melanoma: results from a phase III randomized trial. J Clin Oncol 20: 2045-2052

Facchetti F, Previdi S, Ballarini M, Minucci S, Perego P, La Porta CA (2004) Modulation of pro- and anti-apoptotic factors in human melanoma cells exposed to histone deacetylase inhibitors. Apoptosis 9: 573-582

Gottlicher M, Minucci S, Zhu P, Kramer OH, Schimpf A, Giavara S, Sleeman JP, Lo Coco F, Nervi C, Pelicci PG, Heinzel T (2001) Valproic acid defines a novel class of HDAC inhibitors inducing differentiation of transformed cells. EMBO J 20: 6969-6978

Grunstein M (1997) Histone acetylation in chromatin structure and transcription. Nature 389: 349-352

Guo JJ, Li QL, Zhang J, Huang AL (2006) Histone deacetylation is involved in activation of CXCL10 upon IFN gamma stimulation. Mol Cells 22: $163-167$

Huncharek M, Caubet JF, McGarry R (2001) Single-agent DTIC versus combination chemotherapy with or without immunotherapy in metastatic melanoma: a meta-analysis of 3273 patients from 20 randomized trials. Melanoma Res 11: 75-81

Insinga A, Monestiroli S, Ronzoni S, Gelmetti V, Marchesi F, Viale A, Altucci L, Nervi C, Minucci S, Pelicci PG (2005) Inhibitors of histone deacetylases induce tumor-selective apoptosis through activation of the death receptor pathway. Nat Med 11: 71-76

Kato N, Tanaka J, Sugita J, Toubai T, Miura Y, Ibata M, Syono Y, Ota S, Kondo T, Asaka M, Imamura M (2007) Regulation of the expression of MHC class I-related chain A, B (MICA, MICB) via chromatin remodeling and its impact on the susceptibility of leukemic cells to the cytotoxicity of NKG2D-expressing cells. Leukemia 21: 2103-2108

Lee ML, Tomsu K, Von Eschen KB (2000) Duration of survival for disseminated malignant melanoma: results of a meta-analysis. Melanoma Res 10: 81-92

Levy RH, Friel PN, Johno I, Linthicum LM, Colin L, Koch K, Raisys VA, Wilensky AJ, Temkin NR (1984) Filtration for free drug level monitoring: carbamazepine and valproic acid. Ther Drug Monit 6: 67-76

Marks PA, Richon VM, Rifkind RA (2000) Histone deacetylase inhibitors: inducers of differentiation or apoptosis of transformed cells. J Natl Cancer Inst 92: $1210-1216$

Minucci S, Pelicci PG (2006) Histone deacetylase inhibitors and the promise of epigenetic (and more) treatments for cancer. Nat Rev Cancer 6: $38-51$

Munster P, Marchion D, Bicaku E, Schmitt M, Lee JH, DeConti R, Simon G, Fishman M, Minton S, Garrett C, Chiappori A, Lush R, Sullivan D, Daud A (2007) Phase I trial of histone deacetylase inhibition by valproic acid followed by the topoisomerase II inhibitor epirubicin in advanced solid tumors: a clinical and translational study. J Clin Oncol 25: $1979-1985$

Piekarz RL, Robey R, Sandor V, Bakke S, Wilson WH, Dahmoush L, Kingma DM, Turner ML, Altemus R, Bates SE (2001) Inhibitor of histone 
Valproate and chemoimmunotherapy in advanced melanoma

A Rocca et al

deacetylation, depsipeptide (FR901228), in the treatment of peripheral and cutaneous T-cell lymphoma: a case report. Blood 98: 2865-2868

R Development Core Team (2006) R: A Language and Environment for Statistical Computing. R Foundation for Statistical Computing: Vienna, Austria. ISBN 3-900051-00-3 [http://www.R-project.org]

Ramalingam SS, Parise RA, Ramanathan RK, Lagattuta TF, Musguire LA, Stoller RG, Potter DM, Argiris AE, Zwiebel JA, Egorin MJ, Belani CP (2007) Phase I and pharmacokinetic study of vorinostat, a histone deacetylase inhibitor, in combination with carboplatin and paclitaxel for advanced solid malignancies. Clin Cancer Res 13: 3605-3610

Rasheed W, Bishton M, Johnstone RW, Prince HM (2008) Histone deacetylase inhibitors in lymphoma and solid malignancies. Expert Rev Anticancer Ther 8: $413-432$

Rasheed WK, Johnstone RW, Prince HM (2007) Histone deacetylase inhibitors in cancer therapy. Expert Opin Investig Drugs 16: 659-678

Ridolfi R, Chiarion-Sileni V, Guida M, Romanini A, Labianca R, Freschi A, Lo Re G, Nortilli R, Brugnara S, Vitali P, Nanni O, Italian Melanoma Intergroup (2002) Cisplatin, dacarbazine with or without subcutaneous interleukin-2, and interferon alpha- $2 \mathrm{~b}$ in advanced melanoma outpatients: results from an Italian multicenter phase III randomized clinical trial. J Clin Oncol 20: 1600-1607

Ronzoni S, Faretta M, Ballarini M, Pelicci P, Minucci S (2005) New method to detect histone acetylation levels by flow cytometry. Cytometry A 66: 52-61
Saunders NA, Popa C, Serewko MM, Jones SJ, Dicker AJ, Dahler AL (1999) Histone deacetylase inhibitors: novel anticancer agents. Expert Opin Investig Drugs 8: $1611-1621$

Sinha R, Moliffe R, Scurr M, Vidal L, Engelholm SA, Buhl Jensen P, Normann A, Li S, De Bono J, Lassen U (2007) A phase I/II study of the safety and anti-cancer activity of IV-administered belinostat (PXD101) plus carboplatin $(\mathrm{C})$ or paclitaxel $(\mathrm{P})$, or both in patients with advanced solid tumors. J Clin Oncol (Meeting Abstracts) 25: 3574

Soengas MS, Capodieci P, Polsky D, Mora J, Esteller M, Opitz-Araya X, McCombie R, Herman JG, Gerald WL, Lazebnik YA, Cordón-Cardó C, Lowe SW (2001) Inactivation of the apoptosis effector Apaf-1 in malignant melanoma. Nature 409: 207-211

Soengas MS, Lowe SW (2003) Apoptosis and melanoma chemoresistance. Oncogene 22: $3138-3151$

Therasse P, Arbuck SG, Eisenhauer EA, Wanders J, Kaplan RS, Rubinstein L, Verweij J, Van Glabbeke M, van Oosterom AT, Christian MC, Gwyther SG (2000) New guidelines to evaluate the response to treatment in solid tumors. European Organization for Research and Treatment of Cancer, National Cancer Institute of the United States, National Cancer Institute of Canada. J Natl Cancer Inst 92: 205-216

Valentini A, Gravina P, Federici G, Bernardini S (2007) Valproic acid induces apoptosis, p16INK4A upregulation and sensitization to chemotherapy in human melanoma cells. Cancer Biol Ther 6: 185-191 